\title{
THE NARRATIVE-DIGITAL APPROACH IN THE LITERARY EDUCATION OF PHILOLOGISTS
}

\author{
Nataliia Kolomiets ${ }^{1}$, Nataliia Yaremenko ${ }^{2}$, Tetiana Mishenina ${ }^{3}$, Nataliia Kharadzjan ${ }^{4}$, Iryna Kohut ${ }^{5}$, and Roman \\ Pavliuk 6,*
}

1 Kryvyi Rih State Pedagogical University; kolomiets_n1@ukr.net

2 Kryvyi Rih State Pedagogical University; yartala28@gmail.com

3 Kryvyi Rih State Pedagogical University; t.mishenina@gmail.com

4 Kryvyi Rih State Pedagogical University; n.a.kharadzjia@gmail.com

5 Poltava V. G. Korolenko National Pedagogical University; irynakohut15@gmail.com

6 Borys Grinchenko Kyiv University; r.pavliuk@kubg.edu.ua

* Correspondence: r.pavliuk@kubg.edu.ua

\begin{abstract}
The article considers the peculiarities of practical implementation of the narrative-digital approach in the process of studying disciplines of literary cycle at philological faculties. The authors emphasize that the key to the effective transition to distance and combined forms of studying is creation of a productive national information and didactic space, with involvement of IT and appropriate level of training of all participants in the pedagogical process. Under these conditions, the application of the narrative-digital approach is promising, which in literary education of philologists is based on interdisciplinary interactive basis, which combines possibilities of narrative methods with computer technology. The integration of digital technologies into philological field causes a number of methodological difficulties, requires all subjects of educational activity to develop digital skills that are not related to professional humanities knowledge, but meet the requirements of trained competitive and highly qualified specialists. The authors conducted a sociological study on the readiness of students of philological specialties of pedagogical universities to implement the narrative-digital approach to educational practice. Research provides optimal software that allows you to implement this approach in practice, offers a selection of didactic tasks, substantiates feasibility of their use in classes of different types.
\end{abstract}

Keywords: narrative-digital approach; literary education; ICT; digital narrative; storytelling.

\section{Introduction}

The latest transformations of the social world towards the technosphere and the deepening of globalization processes have conditioned to a change in the traditional cultural paradigm. The level of modern information support creates opportunities for improving approaches to educational activities. Topical tools make promising distance, combined studying, in which a narrative-digital approach can be widely represented.

The challenges facing society during the COVID-19, coronavirus pandemic have mobilized resources to seek new forms of teaching the humanities and at the same time slowed the use of methodologically outdated approaches to teaching. As a result of the epidemic, a new educational space was created in a very short period of time, which is mainly deployed in a distance format with the help of modern information technologies. V. Osadcha, K. Osadchyi, V. Kruhlyk, analyzed the specifics of the didactic paradigm in quarantine and pandemic period, noted that the efforts of most countries "are aimed at preventing the termination of the educational process and the organization of distance studying" (Osadcha et al. 2020). This transition allows synchrony of group communication regardless of location, which is especially important during lockdowns and other quarantine restrictions. According to S. Semerikov, I. Teplytskyi, S. Shokaliuk, "mobile learning allows monitoring of learning in real time and provides high content saturation" 
(Semerikov et al. 2008). A necessary condition for the effectiveness of technological education is the creation of productive national information and didactic space, the involvement of IT, the appropriate level of training of all participants in the pedagogical process.

The implementation of the optimal approach in a pandemic period is coordinated by such organizations as UNESCO, the UN General Assembly, the Council of Europe and others. The result of the Summit according to "Education in Emergencies" in 2019 (Geneva) was the publication of Long-term vision and Action Agenda for education in emergencies data (Education in Emergencies Data 2019), which discusses the need to increase information literacy of teachers, which will contribute modernization of the education system. An extraordinary session of the UNESCO Global Conference (Extraordinary Session on Education post-COVID-19: 2020 Global Education Meeting) is aimed at supporting the industry during such a challenging times, which attempted to solve the problems of deploying hybrid models of learning, digitization of educational programs, the formation of IT literacy among teachers and students (Global Education Meeting Declaration 2020).

Modern realities of the information society have determined the multiparadigm of methodological approaches to teaching humanities. Classes based only on monomodality do not meet the social demands of adaptability of the educational environment, so in the modern educational literary paradigm there is a tendency to a meaningful combination of different information channels, synthesis of text, graphics and voice learning materials. All this can be successfully realized through the application of narrative-digital approach, which in the literary education of philologists is based on an interdisciplinary interactive basis, which combines the possibilities of narrative methods with computer technology. According to H. McLellan, "digital storytelling is a promising instructional strategy as well as an emerging field of study in higher education. Courses on digital storytelling are offered in communications and creative writing programs at a number of universities" (McLellan 2007).

The integration of digital technologies into the philological field causes a number of methodological difficulties, requires all subjects of educational activity to develop digital skills that are not related to professional humanities knowledge, but meet the requirements of training competitive and highly qualified specialists. The application of this approach to the organization of educational space makes it possible to adapt to the requirements of the information society, to strengthen the connection between the content of education and the daily activities of young people, to strengthen the practical significance of the results.

According to the experience gained during the quarantine restrictions of the 2019-2020 academic years, the organization of qualitative distance studying using digital technologies requires expanding the communicative range of classes and increasing the level of media literacy. When studying literary studies courses ("Theory of Literature", "History of Ukrainian Literature", "History of Foreign Literature", etc.), the introduction of a narrative-digital approach seems promising, which will increase student's cognitive activity, develop creative abilities, the ability to produce new ideas and to quickly adapt to new working conditions. The process of creating digital narratives involves painstaking work aimed at studying, selecting and thorough analysis of literary material, writing a script or other text setting, selection of possible implementation options (sound, music accompaniment, and color embodiment), their design, selection of IT software. This approach allows to transfer a significant amount of humanities knowledge in a fairly concentrated digital solution and to present the result of creative activity with the help of IT technologies.

The aim of the research is to find out the peculiarities of the practical implementation of the narrative-digital approach in the process of studying the disciplines of the literary cycle at the faculties of philology. 


\section{Analysis of Publications}

The problem of applying the narrative-digital approach in education has a wide scientific coverage. In the theoretical aspect, the essence of the concept of "narrative-digital approach" is considered in the works of L. Tymchuk (Tymchuk 2015), V. Bykova, M. Leshchenko, L. Tymchuk (Bykova et al. 2017) and others. Researchers note that this approach in education was formed on the basis of the synthesis of oral narrative, digital technologies and the transfer of content through visual image, sound in their complex application. In the researches of G. Barkhuizen (Barkhuizen 2008), X. Li, C. Conle, F. Elbaz Luwisch (Li et al. 2009), A. Korhonen, M. Vivitsou (Korhonen et al. 2019) and others the question of practical application of narrative in the educational process is revealed.

The research of O. Pinchuk, O. Sokolyuk, O. Burov, M. Shyshkina (Pinchuk et al. 2018), E. Fedorenko, V. Velychko, A. Stopkin, A. Chorna, V. Soloviev (Fedorenko et al. 2018) and others are devoted to the issues of informatization of education and formation of digital competence of students.

The scientific literature characterizes the specifics of the components of the audiovisual construct, which is formed using a narrative-digital approach. Possibilities of using musical accompaniment, principles of its selection in designing digital narratives in order to strengthen the pedagogical influence disclosed in the article by N. Pavlenko (Pavlenko 2018). A number of works are devoted to the peculiarities of expressing the graphic mode in the performance of educational tasks. In particular, researchers Liu Z. J., Levina V., Frolova Y. (Liu et al. 2020), N. Ogawa and A. Shimizu (Ogawa and Shimizu 2016), H. Ivanova , O. Lavrentieva, L. Eivas, I. Zenkovych and A. Uchitel (Ivanova et al. 2019) and others provided recommendations on the possibilities of visual design of literary material. These works also contain guidelines for websites that can be used to visualize educational information. The problem of integration of codes of different modalities is elaborated in publications of J. Lim, C. Polio (Lim and Polio 2020), Danielsson K, Selander S. (Danielsson and Selander 2016), A.-L. Godhe (Godhe 2014), F. Serafini (Serafini 2011) and others.

A number of researchers remark that digital storytelling is a powerful pedagogical tool in educational practice. Thus, the potential of the academic use of digital stories, the features of their application in educational activities are revealed in the works of M. Rossiter, P. Garcia (Rossiter and Garcia 2010), C. Shelton, A. Warren, L. Archambault (Shelton et al. 2016), R. Clarke, A. Adam (Clarke and Adam 2012), J. Skouge, K. Rao (Skouge and Rao 2009) and others.

It should be noted that in the scientific literature the narrative-digital approach is interpreted as an ergonomic modern way of expressing ideas. Scientists have raised some problems of its application in the education of students of philological specialties. In particular, the possible forms of digital narratives that should be used in the study of the humanities are given in the article by J. Barber (Barber 2016). K. Düerkop, A. Bakker (Düerkop and Bakker 2018) raised the problems of using narrative digital games in literary education, in particular, an example of design development at its early stage, focused on the formulation of research questions, building design ideas, etc.

\section{Materials and Methods}

After distance studying in the 2019-2020 academic year, we conducted a survey of students of philological faculties of Kryvyi Rih State Pedagogical University (98 people) to study the effectiveness of the educational process using ICT and the features of the use of digital narratives. The questionnaire was about such questions:

1. What difficulties did you face in mastering information from professional disciplines during distance studying?

2. What didactic support in the study of Ukrainian and foreign literature created the conditions for better mastering of information? 
3. Which media elements (visual, audio or a combination of them) reflect the content of the disciplines of the literary cycle best?

4. What forms of educational activities did you lack during quarantine restrictions?

5 . Does the use of digital narratives during the lecture contribute to effective educational communication?

6. Are you sufficient for distance learning of previously acquired skills of ICT users?

7. Do you have enough previously acquired skills of ICT for distance studying?

8. Would you attend a special course aimed at improving ICT skills?

The majority of students $(97.8 \%)$ noted that classes conducted using video communication technologies (ZOOM, Google Meet, Skype, etc.) require greater cognitive visualization of philological knowledge. With a significant information load, they lacked a graphical interpretation, improved visual support. According to $84.5 \%$ of respondents, the combination of visual and audio media elements contributes to better assimilation of educational information, as it allows using all channels of perception due to a qualitatively new level of presentation of educational material. $59.2 \%$ of students noted that they lacked teamwork during distance studying. They noted that during the quarantine period they felt the need for group collaboration, so they expressed a desire to perform educational tasks that require collective elaboration and solutions. The majority of students $(79.6 \%)$ noted the effectiveness of educational communication with the use of digital narratives during the lecture. Such information is characterized by dynamism, which, according to respondents, enhances cognitive activity. $58.2 \%$ of respondents expressed a desire to attend a special course aimed at improving ICT skills.

The results of interviews, questionnaires, observations, analysis of the level of educational activity during distance studying serve as a sufficient argument for the introduction of narrative-digital approach in the study of disciplines of the literary cycle. We consider it logical to apply this approach both during classroom classes (lectures and practical's) and for tasks submitted for independent study.

\section{Results}

The digital society aims to create a unique educational environment in which the main parameters would be to stimulate the intellectual progress of students, diversify their ways of thinking, the optimal organization of self-directed heuristic-contextual learning. The narrative-digital approach allows intensifying the process of information perception by expanding the channels, to dynamize the process of its processing and dissemination, to create a harmonious fruitful collaboration of students and teachers.

The narrative-digital approach is interpreted by us as the construction of an educational matrix by involving IT-technologies in the creation of a multimodal narrative in order to expand the spectrum of perception of rational-logical and sensory-sensory information. Digital narratives in literary education help to increase the effectiveness of literary studies, which can be classified as an innovative method of modeling digital literary history, which contributes to the formation of literary and information-digital competencies of future philologists.

Within the information-digital educational model, the narrative is interpreted as one of the parameters of the communicative goals, which is not only crucial for the transmission of information, but also for reflection on the story. In general, human experience is presented as a kind of story.

Among the leading vectors of the digital narrative are the followings:

- segmentation;

- logical sequence of the story, that is to comprise every bit of the story;

- the relationship between the narrator and the recipient on the emotional and semantic levels;

- proportional involvement of speech, visual, audio components by using the potential of ICT;

- interactive form of interaction with the audience. 
Digital narrative in philological education is used in various forms of educational activities. We have developed a model for introducing a narrative-digital approach to the literary education of the philological faculties of the Pedagogical University (see Figure $1)$.

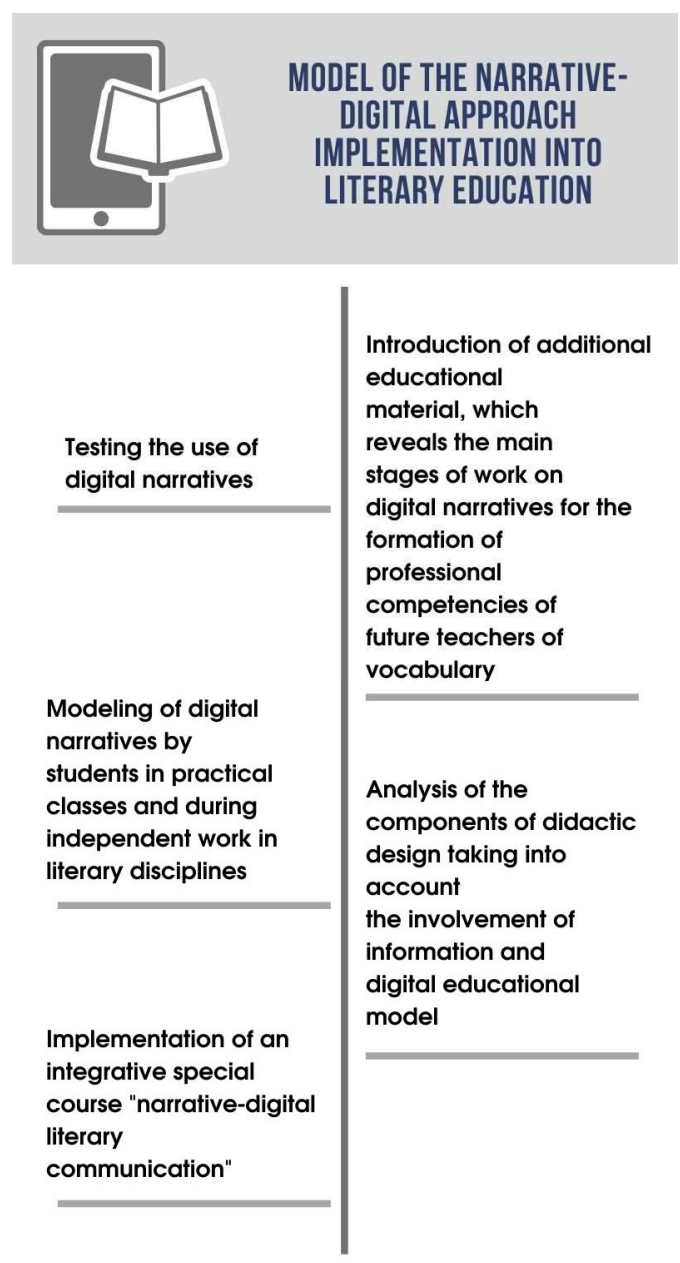

Fig.1 Model of introducing the narrative-digital approach implementation into literary education

Since it is a structural part of the lecture course, it is involved at the stage of updating previously acquired knowledge or as a motivational stage in the study of the topic. Creation and representation of digital narratives by students takes place in practical classes and during the tasks of independent work.

The optimal design of the narrative-digital content of the training course should be based on a well-thought-out scenario of all participants' interaction in the process. The process of forming students' skills of creating digital narratives actualizes communicative, research, reflective competencies, as well as skills of multimedia and digital tools. The creation of a digital narrative, as a multifunctional, means of learning takes place with the participation of the narrator and recipients, with the involvement of video, audio and verbal channels.

Students of philological faculties mastered the skills required for creating digital narratives for the organization of the educational process in real/virtual space was based on an algorithm based on certain principles of ADDIE (Analysis, Design, Development, Implementation, Evaluation). (see Figure 2) 

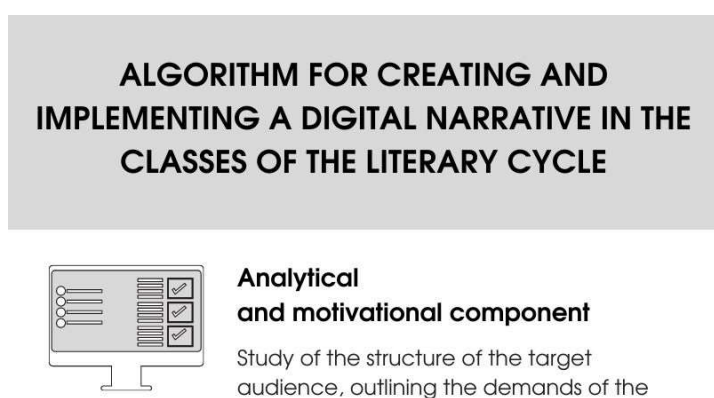

Analytical

and motivational component

Study of the structure of the target audience, outlining the demands of the educational environment, creating a logical and convincing motivation: the distribution of functional roles in the group.
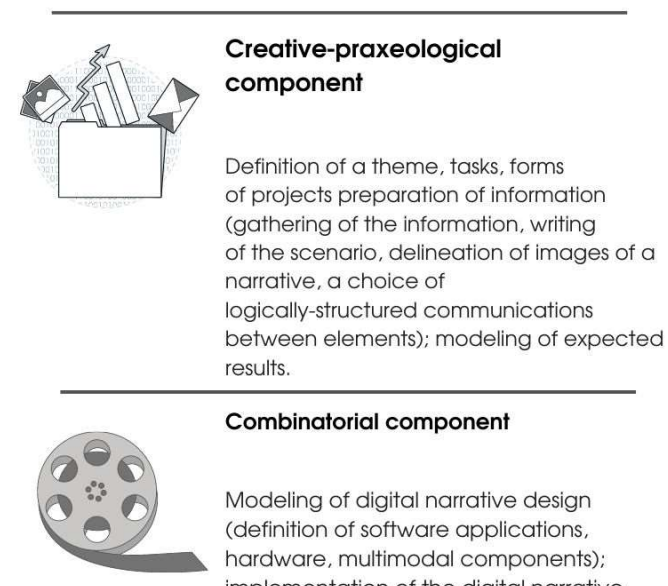

Combinatorial component

Modeling of digital narrative design (definition of software applications, hardware, multimodal components); implementation of the digital narrative scenario: creation of an integral construct of the primary version.

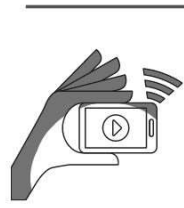

Презентаційно-оцінний компонент

Representation of the digital narrative: involvement of control and measuring materials; analysis of the project reception.

Fig.2 Algorithm for creating and implementing a digital narrative in the classes of the literary cycle

Digital narrative is the answer to the challenges of the 21st century. Due to the actualization of this educational toolkit the latest literacy is formed, which is realized in the synthesis of digital (communication skills formed by expanding the media community), global (ability to perceive, interpret and assimilate verbal information), visual (ability to interpret information using visual images), technology ability to use IT technologies and devices to build a communicative environment) competencies (Brown et al. 2005).

The structure of the digital narrative is determined by seven parameters outlined by the CDS (Digital Narrative Center, Berkeley, California, USA) (see Figure 3). 


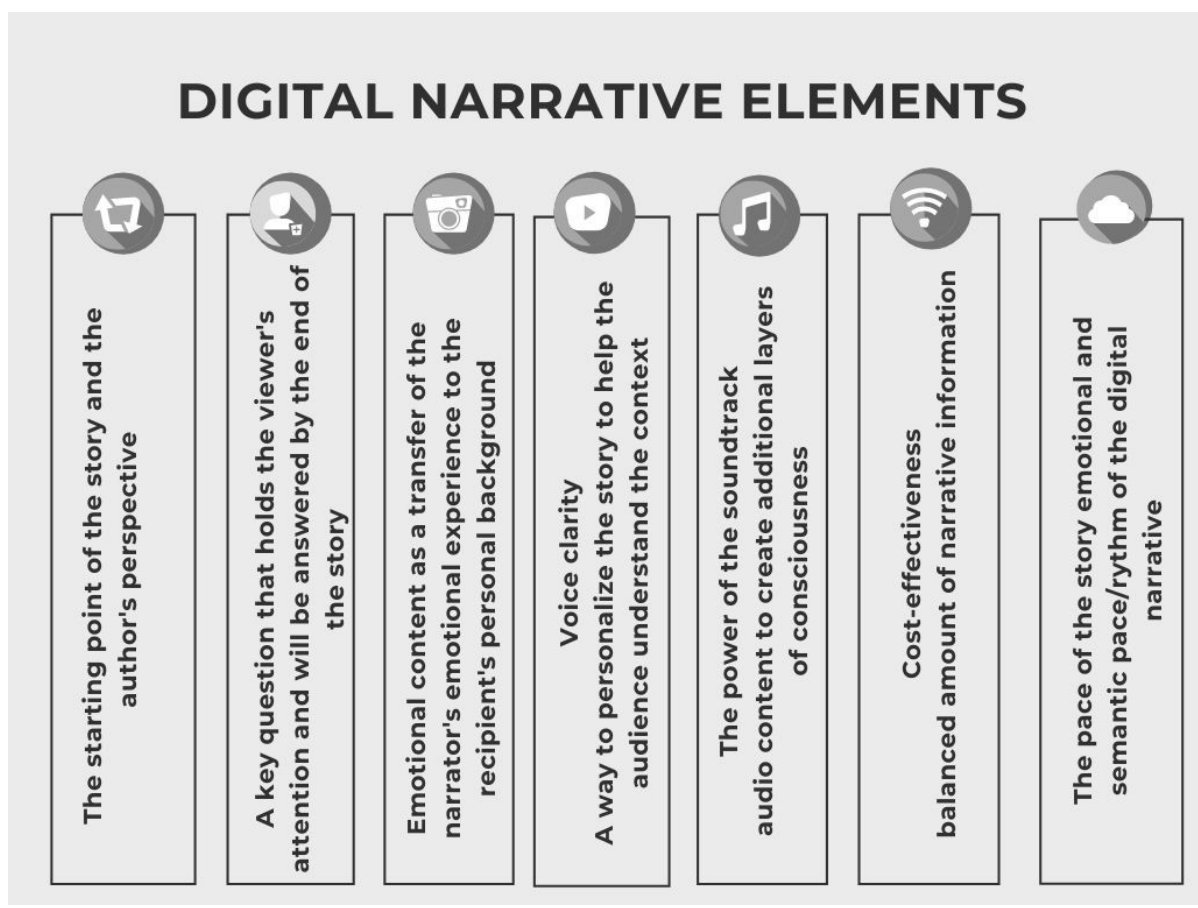

Fig. 3 Digital narrative elements

In the process of creating this didactic construct, various digital media and software are used. Consider some formats of implementation of the digital narrative in the classes for philological faculties of pedagogical universities.

We singled out static and dynamic digital narratives. Static digital narratives are modeled using different types of audio editors. Most of them are adapted for trimming, combining, overlapping tracks (this will come in handy when compiling behind-the-scenes texts and soundtracks). Among the most popular applications are Beautiful Audio Editor, TwistedWave Online, Audiotool, BearAudioTool, Diktorov.net, EasyVoiceRecorder and many others.

Before announcing the work on the median narrative, we have completed the preparational stage: students were asked to critically analyze digital narratives posted on platforms such as: Dramatic Question, Verse or StoryMapJS. In particular, the correctness of implementing the author's position in them, the expediency of selecting the used verbal, audio and visual content, the possibility of alternative project options are commented.

Creating a static digital narrative using a narrative-digital approach is as follows:

- study of a visual object (photo, collage, drawing in PNG format),

- selection of the necessary content, analysis of its relevance;

- development of a script (150-200 words), substantiation of the source base involved in the project information,

- reading off-screen text,

- soundtrack selection,

- installation of a media project,

- saving as an MP3 file and exporting it to the YouTube platform, faculty channel.

In the process of studying the course "History of Ukrainian literature of the 40-50s of the twentieth century" students were asked to create a digital narrative, commenting on a number of visual objects (see Figure 4). 

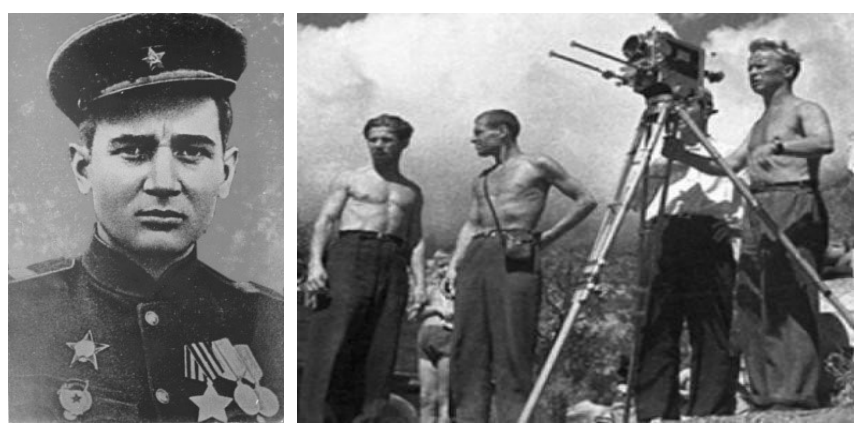

Fig. 4 Visual content for the static digital narratives creation

Below the examples of students' work may be found. Extracts from scripts:

There are already many books on my mental bookshelf, but not everyone has a portrait of its creator. The figure of Oles Honchar appeared on my reading horizon thanks to my grandmother, who, adjusting her thick glasses on her old nose, read about Bohdan Kolosovskyi, Tanya, Dukhnovych, Olha Hrechanka ... Oles Honchar in the photo is still very young. 25 years - is it age? However, in the eyes of the future writer so much pain! Involuntarily, the words from the novel "Man and Weapon" come to mind: "Studbat was bleeding ...". Yes, the years when the artist was forced to wear a military uniform, left a deep mark in his soul. Students-students left this world before his eyes, he survived a year of German captivity, miraculously escaped repression after his release, fought to victory with a weapon in his hands...

"Earth, a house on this earth, people's lives in this house" - so paradoxically simple and at the same time fully described the meaning and idea of Alexander Dovzhenko's film "Earth". This work of cinematography became a synthesis of romantic sublimity, expressionism and realism. A film that has created an unprecedented resonance in world cinema and continues to encourage contemporary artists to co-create (a project of the Ukrainian ethno-chaos group "Dakha Brakha").

"Homer of the World Cinema" Note that the format of a comparable historical and literary digital narrative on the ground of historical correlation, in our opinion, may well comprise observation of fragments of the historical original and literary translation / interpretation into other languages - audio accompaniment (Yaroslavna's Lament; Testament (Slavic languages translated)), for example, in the context of developing the worldview of future philologists, in which the conceptual guidelines are history, art, literary, historical memory, culture, cultural, historical and state development. This digital chain will have an educational character; contribute to the formation of literary taste, historical competence, and language culture.

Digital narrative, as a personal creative narrative, is based on a combination of a verbal component with a chain of logically conditioned audiovisual images. Thus, in the conditions of systematic work on designing projects of this type, actualizing epistemological and emotional aspects of learning and integrating theoretical knowledge into reflective narration, students improve the ability to meaningfully and succinctly represent different semantic concepts of literary courses: cultural discourses, stylistic dominances artists, their "curriculum vitae", etc.

The directions of reproduction of the multimedia image of the biographical way of the writer can have the following digital format:

1. Writer - memories (diary; lyrical digression, which reproduces the memories of becoming (childhood, adolescence, maturity as a stage of artistic creativity) and prolongation of the philosophy of biography (author's position, which reflects the events reproduced in artistic discourse, interprets them from the position of the philosopher. The biographical path of writers whose diaries have become public property (Taras Shevchenko, Oleksandr Dovzhenko, Ostap Vyshnya, Mykhailo Stelmakh, Hryhir 
Tyutyunnyk) can be considered, as well as the interpretation of the way of life in close connection with the historical and cultural development of the nation.

Autobiographical correlates also include memoirs, lyrical digressions of writers, which are reproduced in an artistic format (Taras Shevchenko (a cycle of poetry of sacred content); Ivan Franko ("Moses"); Ivan Bagryany ("Garden of the Gethsemanes"), prose works that interpret national history through the prism of the national idea ("Zahar Berkut","Borislav laughs"), Lesya Ukrainka (intimate lyrics; civic lyrics; historical and philosophical interpretation of domestic and world events) ), Ostap Vyshnya (lyrical digressions in the literary text of the developed genre of humor, smiles), Mykhailo Stelmakh (children's literature), Vsevolod Nestayko (children's literature), Mykola Vingranovsky (children's prose).

It is effective to develop a digital code that contains the facts of the biographical path, which represents a pattern of imitation (certifies a stable civic position). In order to develop such a representative, it is necessary to apply synchronous / diachronic criteria; criteria of socio-cultural and historical-political correlation.

2. Writer - literary-critical, public activity (the writer's personality is uncovered through literary-critical articles; public speeches, etc.). Such works represent creative-literary search and literary-critical analysis, which allows to reproduce the model of the writer's idiosyncrasy, to comprehend the culture of fiction of the studied stage. In particular, the development of Ukrainian literature through the literary-critical discourse of Hryhoriy Kvitka-Osnovyanenko, Ivan Franko, Maksym Rylsky (including those concerning methods and techniques of translation - on the example of Slavic literature), Oles Honchar, Lina Kostenko allows to reproduce the correlation of domestic and world literary discourses in the aspect of choosing the method of artistic narrative.

Literary narratives reproduce in their logical (stages of becoming a writer as a master; stages of creating a work of art / works of art; determination of the plot / images of a work of art by social-cultural context) and systemic sequence information about the writer's biography, covering factors influencing his worldview. turn reproduced in the author's position, which translates the ideological icons in artistic discourse. It's about digital history: the life of the writer; artistic work in the context of national and world literature in particular, history as a retransmission of the development of human culture in general. An interesting experience in designing and implementing a dynamic narrative-digital construct is the work of generalizing theoretical and literary knowledge. An example is a project initiated by 2nd year students "Stylistic Dominants of Art Epochs".

This construct was created in the doodle video format. At the heart of this form is the principle of intuitive drawing, which allows a person in a culture focused on verbal information, to actualize the visual system of perception. Spontaneous markings made in the process of active listening or contemplation have been observed to significantly improve the memorization of material, help to absorb information more deeply, and attract emotional experience. Thus, the digital narrative, created with the involvement of this type of content is aimed primarily at developing students' skills to visualize the imaginary, highlight the main thing, systematize information.

In addition to video doodles, you can use animated media or video editing to create a dynamic digital narrative. This can be a project with the use of tape or video. Such a digital narrative is concise, interprets literary concepts as simple graphic images, contains integrative knowledge.

There is a significant amount of software for video editing. It works on both mobile and desktop devices, with different operating systems (there are even cross-platform). These applications have both free and paid content, which allows you to get effective functionality, create the necessary impression, convey the dynamics of the image. All applications require registration. However, it is as simple as possible, via e-mail or social networks, Google / Facebook. Almost all applications allow you to edit video with Drag \& Drop technology, use effects and transitions between video and photo, change video speed, adjust and convert from 2D to stereoscopic 3D, overlay text, captions, sound and 
more. Table 1 provides an overview of the most popular video editors.

Table 1. The most popular video editors

\begin{tabular}{lllll}
\hline \multicolumn{1}{c}{ Name } & \multicolumn{1}{c}{ IP address } & \multicolumn{1}{c}{ Registration } & & \\
\hline VideoPad & & - & Desktop & Free \\
Clipchamp & $\begin{array}{l}\text { clipchamp.com } \\
\text { Free/paid }\end{array}$ & Google/Facebook & Online & \\
HippoVideo & $\begin{array}{l}\text { https://www.hippovi } \\
\text { deo.io/ }\end{array}$ & $\begin{array}{l}\text { Individual } \\
\text { registration }\end{array}$ & Online & Free/paid \\
WeVideo & www.wevideo.com/ & Google/Facebook & Online & Free/paid \\
Wideo & https://wideo.co/ & Google & Online & Free/paid \\
\hline
\end{tabular}

HippoVideo - a platform designed for the following manipulation with video content: compiling video from screenshots or webcams, adding emoji, tags, text tags, etc. The free version allows you to save video as 720 p, the duration of the video should not exceed 1 hour. Modern video editor Clipchamp is relatively free, has an apparently large array of templates. The ability to save videos is limited to SD (480p) format. Purchasing a premium account removes all restrictions and allows you to export videos in $720 \mathrm{p}$ and 1080p. The editor also allows you to choose different video ratios 1: 1, 9:16, 4: 3 or 16: 9. The paid version of the WeVideo cloud online platform allows you to use premium editing functions: green screen, voice acting, slow motion, screen display and synchronization on iOS, Android web platforms and other functions. Kizoa is used to create videos and slide shows. This online service does not require registration, has an intuitive interface, so it is suitable for beginners. VideoPad has only a desktop version and allows you to edit large files. These applications can be used to implement practical tasks in classes in literary disciplines when creating a digital narrative.

Also a significant niche is occupied by video editors that are installed on mobile devices (phones, tablets) and run on Android / IOS. The advantages of such editors are constant availability, ease of use, and an intuitive interface. InShot, VivaVideo, GoPro Quik, Videoshop and others, that enable compiling video clips according to the plan, add audio, text, make correct transitions, chromakey, slow mo, apply the necessary visuals to sound effects, format the video.

Creating a dynamic digital narrative requires certain time, due to its meaningfulness and requirements for collective forms of interaction, so, in our opinion, creating calls for group collaboration. Algorithm for creating a dynamic digital narrative:

- defining the purpose and objectives of the project, outlining the perspective of the story (external-internal), creating a script application;

- script development: history structure, conflict, leitmotif, prescribing details, etc .;

- storyboard (selection and arrangement of audio and visual material that would be associated with the created media text, possibly with the use of resources VideoScribe, Powtoon, GoAnimate);

- reading off-screen text, shooting the author's video content;

- sound library selection;

- editing and publication of a digital narrative.

An example of such a digital narrative is the projects "I read modern", "Outside the program" launched at the Faculty of Ukrainian Philology.

Modern digital capabilities allow in the process of analysis of a work of art to realize literary reflection. With the help of a hypertextual sentence at the level of the electronic corpus it is possible to integrate information related to psychology (within the framework of our research we are primarily talking about the structure of personality; value orientations that determine a person's orientation); sociology (factors of society devel- 
opment, formation of constitutional rights of a citizen); history (historical commentary on the era, events, facts that are reflected in the literary work). The possibility of collecting under one denominator of intersectoral information, which provides a polysemantic perspective in the consideration of a literary work, allows you to build a concept of literary reality. The study of the content of a work of art, in turn, in the narrative representation, involves the interpretation of themes and issues from the standpoint of the influx of aspects, contributes to the rethinking of fundamental social correlates.

Thus, the narrative-digital approach used in the literary cycle creates the conditions for integration into the educational process of verbal information, design and technology, which forms students' critical thinking, ability to analytical work, emotional intelligence, creativity, narrative theory and application.

Further introduction of the narrative-digital approach in literary education seems promising. This requires increasing the level of IT literacy of students, which is possible by introducing an additional special course and making appropriate additions to the curriculum.

Integrative special course "Narrative-digital literary communication" is focused on 3rd year students, the amount of study load - 1 ECTS credit, the place of experimental implementation - the Faculty of Ukrainian Philology of Kryvyi Rih State Pedagogical University. The content of the special course can be implemented in laboratory-practical classroom and individual-extracurricular format. It is based on the idea of narrative-digital approach in literary education, which involves the interpretation of literary concepts, events, phenomena through the use of various didactic models, which are practically implemented in static and dynamic media resources. Constructing a complete (systemic) idea of the object under study becomes scientifically sound by analyzing different points of view, their systematization, taking into account the extent to which the outlined paths contribute to the resolution of contradictions.

The proposed special course may contain the following thematic blocks:

1. "Digital laboratory of biographical history of the writer" (life story, reflected in the work of art). Such digital narratives reveal the factors of the master's personality development, the events that influenced the formation of his worldview to one degree or another, determined the aesthetic determinants of idiostyle.

2. "The art world in the lens". The content of such a digital narrative may contain excerpts from diaries (T. Shevchenko, O. Dovzhenko, O. Honchar); literary-critical articles; figurative reproduction of different periods of life in art.

3. Album-animation "Stylistic dominants of artistic epochs".

4. Collective creation of digital stories "Studio of recordings of synesthesia kaleidoscopes".

5. Discussion club "Literary education as a way to learn about the world".

Cognitive-creative narrative generalizations, reproduced in images, artistic details, onyms that have socio-cultural correlation, visual dynamics, are associated with a certain conclusion about the course of socio-cultural / historical event, reflective practice of awareness of socio-cultural reality. Therefore, the proposed special course involves understanding the unity of scientific and creative search for artists of different generations, the study of idiostyle as a model of verbal painting, artistic reproduction of the biographical path and worldview through the prism of the literary direction.

\section{Discussion}

The introduction of the narrative-digital approach into the educational process demonstrated its socio-cultural and pedagogical significance. After the content-procedural implementation of the model, testing of the developed tasks aimed at creating digital narratives, we conducted a survey and survey of students. Information was collected in order to determine the peculiarities of the educational process using digital narratives; study of stages s characteristics of cognitive-affective, social interaction 
between students in the process of creating this didactic model; description of the emotional aspects of its use by future philologists.

Here are the questions of the questionnaire:

1. Does digital history within the disciplines of the literary cycle successfully perform independent and individual tasks?

2. How do the proposed narrative didactic materials help you to provide a rational / critical assessment of the proposed educational information?

3. Describe the logical and aesthetic qualities of digital stories created in the lessons of the literary cycle.

4. Describe the quality of the proposed scenery of content, values, aesthetic qualities in the perception of media narratives.

5. To what extent, in your opinion, the digital narrative allows to draw conclusions to the studied topic in the literary and cultural aspects? raised?

6. What digital equivalents contribute to a deeper understanding of the issues

7. Did digital literary stories motivate you to achieve your educational goals?

8. Did digital literary stories motivate you to deepen your knowledge in order to resolve contradictions in the development of the literary process; understanding of its patterns?

9. Evaluate the feasibility of creating a digital portfolio as an electronic argument for the development of personal reflection on the content of teaching disciplines of the literary cycle.

During the survey, it was suggested to answer the following questions:

- Evaluate the effectiveness of digital stories from the standpoint of enhancing the development of skills to work in a group: teamwork and collaboration.

- Describe the use in digital narratives of the axiology of the electronic artistic word (spectral information modalities).

- Did the digital narrative contribute to the development of skills to feel the ability of others to successfully solve the problem?

- Describe the dynamics of your personal vision of the educational content of the disciplines of the literary cycle in the extrapolation of narrative didactic units.

The conducted surveys and questionnaires allowed highlighting a number of benefits that students felt in the implementation of the narrative-digital approach. In particular, $79,4 \%$ noted that the introduction of this approach had a positive effect on the assimilation of educational material, $20,6 \%$ could not decide on the answer. None of the respondents noticed a negative impact $(0 \%)$.

Respondents noted that the work on creating a digital narrative contributed to the intensification of cognitive activity, namely: structuring the material; deeper understanding of the work; search for additional information, etc. In addition, all students noted that the creation of a digital narrative stimulated them to active creativity, contributed to the emergence of emotional response when working on writing a screenplay, intensified empathy. According to respondents, the use of narrative-digital approach allows

- to reproduce in digital space own associative fields $(58,2 \%)$;

- to form the skills of structuring a significant amount of information (84, 5\%);

- practice in modeling information design based on a combination of audiovisual and literary component $(97,8 \%)$.

$78,4 \%$ of respondents indicated that during the activities aimed at making an integrated multimedia product, the interaction of students was established. Being within creative groups united by a common strategy, they experience different types of cooperation and communication (exchange of information of historical and literary content, choice of a convenient ICT platform, selection of audiovisual resources, understanding of design, etc.). 
The survey also touched upon the problems of developing students' digital competence. $80,4 \%$ of respondents said that to fully work on the design of the story had to master additional digital tools. They also pointed to the low level of development of their own digital competence. This allows us to talk about the lack of orientation of professional training of philologists on the use of ICT in the educational process and the feasibility of introducing the proposed model in the teaching of students-linguists.

\section{Conclusions}

The narrative-digital approach in literary education first of all forms in students the ability to model digital literary history, which increases the level of subject and information-digital competencies of future teachers of vocabulary. Working on digital narratives meets the expectations of young people who live by the realities of a dynamic information society.

Since the narrative-digital approach involves the study of the architecture of the world, reproduced in the work of art, the modeling of knowledge about reality based on the studied work may involve the ambiguity of references. The ambiguity of meanings encourages the presentation of information that contains integrative knowledge. In this way, we can talk about the possibility of modeling by means of a digital narrative of one's own reality, and the semantic analysis of fragments of the relevant plot components can be based on both an absolute understanding of the object of knowledge and a relative one. The above allows us to classify the digital narrative as a method of teaching, because its application involves the structuring of human knowledge (a priori / a posteriori) and serves as a way of thinking in the study of artistic discourse.

Recourse to the digital narrative (static and dynamic) seems possible both in the lecture course and in practical classes and during the tasks of independent work. Narrative as a method of scientific research provides the most optimal learning outcome, as it correlates with self-study, determines the trajectories of increasing the levels of professional competencies in the process of studying the disciplines of the literary block. The introduction of a narrative-digital approach to educational activities contributes to the modification of possible forms of work in the study of literary courses, the adjustment of interaction between teachers and students and the establishment of collaboration in student groups.

The software that can be used to model static and dynamic digital narratives is different. Among the most popular applications suitable for creating static narratives are Beautiful Audio Editor, TwistedWave Online, Audiotool, BearAudioTool, Diktorov.net, EasyVoiceRecorder and more. The following video editors can be used to create a dynamic digital narrative VideoPad, Clipchamp, HippoVideo, WeVideo, Kizoa, etc.

The proposed model of introduction of narrative-digital approach in literary education creates the following advantages:

- encourages students to research activity, involving them in dynamic interactive learning processes;

- in the process of selection and systematization of content, develops critical thinking, logic, argumentation of judgments;

- improves the skills of verbalization of thought;

- forms the independence of views, a clearly defined point of view, creativity in the compiled materials and the actual author's content;

- gives the opportunity to form an alternative virtual reality, designed in a given educational aspect in a compact format;

- creates a positive emotional background of pedagogical design of the lesson;

- effectively encourages students to communicate in the group and beyond;

- promotes the development of multi-channel intelligence;

- corrects and improves IT competence.

Among the prospects for the introduction of narrative-digital approach in literary education are: 


\author{
- development and introduction of an integrative special course aimed at improving \\ ICT skills; \\ - transformation of the methodology of teaching basic courses in literature, the dis- \\ closure of their potential, taking into account the technological achievements of the in- \\ formation society.
}

Author Contributions: Conceptualization, N. Kharadzjan and T. Mishenina; methodology, N. Yaremenko; formal analysis, N. Kolomiets; investigation, N. Kharadzjan; resources, N. Kharadzjan; writing-original draft preparation, I. Kohut; writing-review and editing, R. Pavliuk; visualization, N. Kharadzjan. All authors have read and agreed to the published version of the manuscript.

Funding: This research received no external funding.

Conflicts of Interest: The authors declare no conflict of interest.

\section{References}

(Osadcha et al. 2020) Osadcha K., Osadchyi V., Kruglyk V. 2020. The role of information and communication technologies in epidemics: an attempt at analysis. Ukrainian Journal of Educational Studies and Information Technology 8(1): 62-82.

(Semerikov et al. 2008) Semerikov S., Teplytskyi I., Shokaliuk S. 2008. Mobilne navchannia: istoriia, teoriia, metodyka. Informatics and information technologies in educational institutions 6: 72-82.

(Education in Emergencies Data 2019) Education in Emergencies Data: A Long-Term Vision and Action Agenda (USAID MEERS program, NORRAG, INEE, 2019), https://drive.google.com/file/d/1PTfuHFNH4xO7y3jCUR8zP0UJrtAnfylW/view. Accessed 12 Dec 2020.

(Global Education Meeting Declaration 2020) Extraordinary Session of the Global Education Meeting, Education post-COVID-19: 2020 Global Education Meeting Declaration (UNESCO, 2020). https://unesdoc.unesco.org/ark:/48223/pf0000374704. Accessed 12 Dec 2020.

(McLellan 2007) McLellan H. 2007. Digital storytelling in higher education. Journal of Computing in Higher Education 19: 65-79.

(Tymchuk 2015) Tymchuk L. 2015. Designing the process of creating digital narratives for future teachers. Pedagogical sciences: theory, history, technology innovation. 4(48): 376-389.

(Bykov et al. 2017) Bykov V., Leshchenko M., Tymchuk L. 2017. Digital humanistic pedagogy. Kyiv: Institute of Information Technologies and Learning Tools of the NAES of Ukraine.

(Barkhuizen 2008) Barkhuizen G. 2008. A narrative approach to exploring context in language teaching. ELT Journal. 62(3): 231-239.

(Li et al. 2009) Li X., Conle C., Elbaz-Luwisch F. 2008. Shifting Polarized Positions: A Narrative Approach in Teacher Education. New York: Peter Lang.

(Korhonen and Vivitsou 2019) Korhonen A., Vivitsou M. 2019. Digital storytelling and group work: integrating the narrative approach into a higher education computer science course. ITiCSE '19: Proceedings of the 2019 ACM Conference on Innovation and Technology in Computer Science Education. 140-146.

(Pinchuk et al. 2018) Pinchuk O.P., Sokolyuk O.M., Burov O.Yu., Shyshkina M.P. 2018. Digital transformation of learning environment: aspect of cognitive activity of students. CEUR Workshop Proceedings 2018, 90-101.

(Fedorenko et al. 2018) Fedorenko E.H., Velychko V.Ye., Stopkin A.V., Chorna A.V., Soloviev V.N. 2018. Informatization of education as a pledge of the existence and development of a modern higher education. CEUR Workshop Proceedings, 2018, 20-32.

(Pavlenko 2018) Pavlenko N.O. 2018. Music art in designing pedagogical digital narratives. Scientific notes. Series: Pedagogical sciences. 163: 115-119.

(Liu et al. 2020) Liu Z.J., Levina V., Frolova Y. 2020. Information Visualization in the Educational Process: Current Trends. International Journal of Emerging Technologies in Learning (iJET). 15(13): 49-62.

(Ogawa and Shimizu 2016) Ogawa N., Shimizu A. 2016. Visualization of extra curriculum education for promoting active learning. IEEE International Conference on Teaching, Assessment, and Learning for Engineering (TALE), 7-9 Dec 2016. 101-108.

(Ivanova et al. 2019) Ivanova H.I., Lavrentieva O.O., Eivas L.F., Zenkovych I.O., Uchitel A.D. 2019. The students' brainwork intensification via the computer visualization of study materials. CEUR Workshop Proceedings 2019. 182-209.

(Lim and Polio 2020) Lim J., Polio C. 2020. Multimodal assignments in higher education: Implications for multimodal writing tasks for L2 writers. Journal of Second Language Writing. 47: 100713

(Danielsson and Selander 2016) Danielsson K., Selander S. 2016. Reading Multimodal Texts for Learning - A Model for Cultivating Multimodal Literacy. Designs for Learning. 8(1): 25-36.

(Godhe 2014) Godhe A.-L. 2014. Creating and Assessing Multimodal Texts. Negations at the Boundary. Level of Thesis, University of Gothenburg, Gothenburg, Sweden.

(Serafini 2011) Serafini F. 2011. Expanding Perspectives for Comprehending Visual Images in Multimodal Texts. Journal of Adolescent E Adult Literacy. 54(5): 342-350.

(Rossiter and Garcia 2010) Rossiter M., Garcia P.A. 2010. Digital storytelling: A new player on the narrative field. New Directions for Adult and Continuing Education. 126: 37-48. 
(Shelton et al. 2016) Shelton C.C., Warren A.E., Archambault L.M. 2016. Exploring the Use of Interactive Digital Storytelling Video: Promoting Student Engagement and Learning in a University Hybrid Course. TechTrends. 60: 465-474.

(Clarke and Adam 2012) Clarke R., Adam A. 2012. Digital storytelling in Australia: Academic perspectives and reflections. Arts and Humanities in Higher Education: An International Journal of Theory, Research and Practice. 11(1-2): 157-176.

(Skouge and Rao 2009) Skouge J.R., Rao K. 2009. Digital storytelling in teacher education: creating transformations through narrative. Educational Perspectives. 42(1-2): 54-60.

(Barber 2016) Barber J.F. 2016. Digital storytelling: New opportunities for humanities scholarship and pedagogy. Cogent. Arts $\mathcal{E}$ Humanities. 3: 1.

(Düerkop and Bakker 2018) Düerkop K., Bakker A. 2018. Design Research in Education: A Practical Guide for Early Career Researchers. Ed. by A. Bakker. Routledge, Abingdon New York.

(Brown et al. 2005) Brown J., Bryan J., Brown T. 2005. Twenty-first century literacy and technology in K-8 classrooms. Innovate: Journal of Online Education. 1(3). Retrieved July 11, 2021 from https://www.learntechlib.org/p/107300/. 